\title{
Does being overweight reduce accuracy in predicting an acute aortic dissection?
}

\author{
Ruggero De Paulis, MD
}

\author{
From the Department of Cardiac Surgery, European Hospital, Rome, Italy. \\ Disclosures: Author has nothing to disclose with regard to commercial support. \\ Received for publication Nov 4, 2017; accepted for publication Nov 15, 2017; available ahead of print Feb 17, \\ 2018. \\ Address for reprints: Ruggero De Paulis, MD, Department of Cardiac Surgery, European Hospital, Via Portuense \\ 700, 00149 Rome, Italy (E-mail: rdepaulis58@gmail.com). \\ J Thorac Cardiovasc Surg 2018;155:1951-2 \\ $0022-5223 / \$ 36.00$ \\ Copyright (C) 2017 by The American Association for Thoracic Surgery \\ https://doi.org/10.1016/j.jtcvs.2017.11.062
}

Predicting the risk of an acute dissection in patients with an aortic aneurysm-whether in the root or in the ascending aorta, whether in patients with connective tissue disease or patients with bicuspid valve-has never been very accurate. Proposing a major heart operation to a symptom-free and otherwise healthy patient with a dilated aorta is not always easy and carries a lot of responsibility for the surgeon and a lot of stress for the patient. On the other hand, postponing the operation and continuing to follow up the aneurysmal growth carries the same amount of concern and sometimes an increased anxiety for the patient. In this respect, we are badly in need of accurate and sound predictive risk scores to help in our decision process.

In this issue of the Journal, Zafar and colleagues ${ }^{1}$ introduce a simpler and easier index for risk estimation in aortic aneurysm. The important news is that height alone is accurate enough to estimate such risk, with an accuracy similar to or perhaps more than that of body surface area BSA. In fact, the same group from the Yale University ${ }^{2}$ provided years ago a very useful chart estimating the risk for rupture or dissection according to the aortic size index (ASI), the ratio between the diameter of the aneurysm and the BSA. The predictive value of the ASI index was decreased in this study, which used a much larger group of patients exclusively with ascending aorta aneurysms. As an important further step, however, it shows that the weight of the patient could be taken out of the picture and the risk better predicted with their new aortic height index. Another group had already proposed a much similar concept of indexing aortic dimension to patients stature, ${ }^{3}$ albeit mostly in cases of connective tissue diseases.

I have always been puzzled by the idea that an increased weight would somehow modify our indication for surgery. Short, hypertensive female patients with large BSA because of a marked increase in body weight are not infrequently seen at our latitude and significantly magnify this problem. For this reason, it is not uncommon in everyday practice in my area to index the aneurysm dimension not to the real BSA but to the ideal BSA for the given patient height. This study adds scientific evidence for such practice, greatly simplifies the surgeon's decision process, and probably

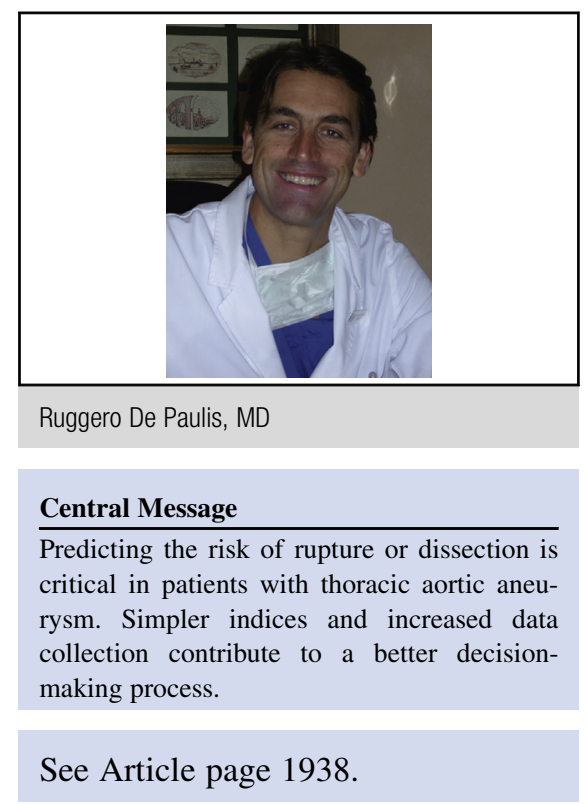

makes the prediction more accurate and useful for obtaining truly informed consent.

Let us consider as an example a 70-year-old woman with a 5-cm ascending aortic aneurysm and a BSA of $1.8 \mathrm{~m}^{2}$. She could either be $1.55 \mathrm{~cm}$ tall with a weight of $76 \mathrm{~kg}$ or $1.75 \mathrm{~cm}$ tall with a weight of $67 \mathrm{~kg}$. In both cases the predictive risk would be moderate (about $7 \%$ per year) according to the ASI, whereas with the new aortic height index, the predictive risk for the shorter patient would be significantly higher (about 12\%).

Adoption of these indices would probably generate criteria for earlier intervention, because both ASI and aortic height index have shown significant risks of dissection, rupture, or death at diameters far below those indicated in the most recent guidelines. ${ }^{4}$ The first hinge point of risk at $5.25 \mathrm{~cm}$ certainly challenges the $5.5-\mathrm{cm}$ limits in the current guideline. This approach is further sustained by the fact that aortic dimension taken at the time of dissection (and used by Zafar and colleagues ${ }^{1}$ in their estimation), are 7 to $8 \mathrm{~mm}$ greater than those before dissection. On the other hand, for a more balanced view, we must also point out that the natural history of the aortic aneurysm stopped with surgery for those patients undergoing elective operation. This implies that surgery before dissection is a competing risk, and in some cases we therefore might be proposing surgery too early in the history of the disease. Furthermore, the presence of significant comorbidities potentially leading to death without 
dissection or rupture adds other confounding factors. Despite some minor concerns regarding the wide applicability of such indices, we can now undoubtedly consider that the use of height alone may be a simpler, easier, and good alternative to the use of BSA for risk estimation.

\section{References}

1. Zafar MA, Li Y, Rizzo JA, Charilaou P, Saeyeldin A, Velasquez CA, et al. Height alone, (rather than body surface area, suffices for risk esti- mation in ascending aortic aneurysm. J Thorac Cardiovasc Surg. 2018; 155:1938-50.

2. Davies RR, Gallo A, Coady MA, Tellides G, Botta DM, Burke B, et al. Novel measurement of relative aortic size predicts rupture of thoracic aortic aneurysms. Ann Thorac Surg. 2006;81:169-77.

3. Svensson LG, Khitin L. Aortic cross-sectional area/height ratio timing of aortic surgery in asymptomatic patients with Marfan syndrome. J Thorac Cardiovasc Surg. 2002; 123:360-1.

4. Baumgartner H, Falk V, Bax JJ, De Bonis M, Hamm C, Holm PJ, et al; ESC Scientific Document Group. 2017 ESC/EACTS guidelines for the management of valvular heart diseases. Eur Heart J. 2017;38:2739-91. 